\title{
Quantification of Viscosity for Solvents-Heavy Oil/Bitumen Systems in the Presence of Water at High Pressures and Elevated Temperatures
}

\author{
Zehua Chen, ${ }^{\dagger}$ Xiaoli Li, ${ }^{\ddagger}$ a and Daoyong Yang* ${ }^{*} \dagger$ \\ ${ }^{\dagger}$ Petroleum Systems Engineering, Faculty of Engineering and Applied Science, University of Regina, Regina, Saskatchewan S4S 0A2, \\ Canada \\ ${ }^{\ddagger}$ Department of Chemical and Petroleum Engineering, University of Kansas, Lawrence, Kansas 66045, United States
}

\begin{abstract}
In this study, a new and pragmatic methodology has been developed to accurately predict the viscosity for light solvents (i.e., methane, ethane, propane, $n$-butane, $n$-pentane, $\mathrm{N}_{2}$, and $\mathrm{CO}_{2}$ )-heavy oil/bitumen/ water systems as a function of pressure in the temperature range of 287.9463.4 K. The LV and ALV ( $\mathrm{L}$ is the oleic phase, $\mathrm{V}$ is the vapor phase, and A is the aqueous phase) phase equilibria of the aforementioned systems are calculated using the Peng-Robinson equation of state (PR EOS) with modified alpha functions and binary interaction parameters (BIPs). The six widely used mixing rules for predicting viscosity of solvents-heavy oil/ bitumen systems pertaining to vapor-liquid equilibria are compared and evaluated, while the linear mixing rule is used for hydrocarbons-water mixtures. Plus, effective density is for the first time successfully introduced into the volume-based mixing rules. The volume-based power law, weightbased power law, and weight-based Cragoe's mixing rules are found to well

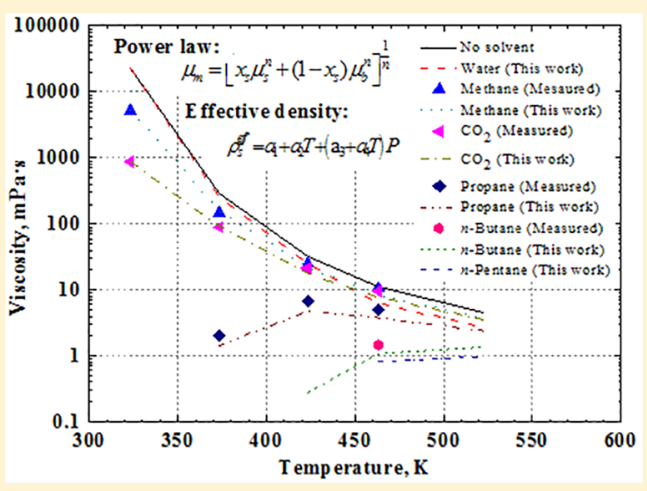
reproduce the viscosity for the aforementioned systems with AARDs of $15.5 \%, 19.0 \%$, and 32.6\%, respectively. Effective density rather than real density of dissolved gas(es) should be used for all of the volume-based mixing rules, while the adjustable parameter in the power law mixing rule has a potential to achieve high generalization if adequate measurements are made available. Although water has a lower diluting ability than other solvents in the same amount of dissolution, it can outperform methane and $\mathrm{CO}_{2}$ in diluting heavy oil/bitumen at high temperatures due to its high solubility. Addition of water can reduce or increase the viscosity of a solvents-heavy oil/bitumen mixture, depending on the ability of solvents and water to dilute heavy oil/bitumen and effects of water on the solvent dissolution. Water molar fraction in feed can exert an effect on the mixture viscosity in LV equilibria through affecting the solvent dissolution but cannot impose an impact on the mixture viscosity at ALV equilibria.
\end{abstract}

\section{INTRODUCTION}

Production of heavy oil/bitumen becomes increasingly important when conventional oil reserves available for development are depleting. Solvent injection/thermal processes which are used to enhance heavy oil/bitumen recovery, e.g., vapor extraction (VAPEX), ${ }^{1}$ cyclic solvent injection $(\mathrm{CSI}){ }^{2}$ steam assisted gravity drainage (SAGD), ${ }^{3}$ steam injection, ${ }^{4}$ and expanding-solvent SAGD (ES-SAGD) processes, ${ }^{5}$ have been widely studied in laboratory and applied in various oilfields. Viscosity reduction due to solvent dissolution/heat transfer is the major mechanism of the aforementioned processes to enhance heavy oil/bitumen production ${ }^{1,6,7}$ because such oil with a significant reduction in viscosity can flow much more easily in porous media. ${ }^{8,9}$ Thus, it is of fundamental and practical importance to accurately predict the heavy oil/bitumen viscosity diluted with solvents/water, while they are frequently injected as viscosity reducer and heat carriers.

Numerous models have been proposed to predict the viscosity for light oils or those of solvents-light oil mixtures but much less for solvent/heavy oil/bitumen systems. Such viscosity models can be divided into three categories: Correlations, ${ }^{10,11}$ mixing rules, ${ }^{12}$ and theory-based models (e.g., corresponding states (CS) model, ${ }^{13}$ friction theory $(f$ theory), ${ }^{14,15}$ and free-volume theory $\left.(\mathrm{FVT})^{16}\right)$. Although the theory-based models are more theoretically sound, they are much more complicated than those simple correlations/mixing rules, which limits their extensive applications in practice. This is especially true for heavy oil/bitumen-containing mixtures due to the fact that heavy oils/bitumens have very complicated compositions and structures to not only make their accurate characterization difficult but also increase the corresponding uncertainties in viscosity modeling. ${ }^{17}$ On the contrary, simple correlations/mixing rules are very convenient to use and thus they have been extensively used in field applications. ${ }^{18}$ The

Received: September 24, 2018

Revised: December 10, 2018

Accepted: December 18, 2018

Published: December 18, 2018 
Table 1. Physical Properties of Different Heavy Oils/Bitumens

\begin{tabular}{|c|c|c|c|c|c|c|}
\hline heavy oil/bitumen sample & $M_{\mathrm{w}}$ & $\mathrm{SG}^{a}$ & $P_{c}, \mathrm{MPa}$ & $T_{c}, \mathrm{~K}$ & $\omega$ & sources \\
\hline Mackay River & 513 & 1.000 & 1.037 & 1019.7 & 2.761 & Zirrahi et al. ${ }^{27}$ \\
\hline Surmont & 539 & 1.009 & 1.018 & 1035.6 & 2.819 & Nourozieh et al. ${ }^{28}$ \\
\hline Cold Lake & 533 & 1.018 & 1.057 & 1040.9 & 2.803 & Mehrotra and Svrcek ${ }^{20}$ \\
\hline
\end{tabular}

main drawbacks of such correlations/mixing rules are that they may yield a large deviation for the predicted viscosity and they are usually used for a specific sample/mixture under certain conditions. ${ }^{19}$ This is especially true for correlations as functions of temperature, pressure, or other parameters such as molecular weight because the coefficients must be retuned for a new sample or mixtures. ${ }^{20}$ Still, some simple mixing rules with one or without any adjustable parameters are found to be sufficiently accurate for estimating viscosities for heavy alkane/ toluene-heavy oil/bitumen mixtures under a wide range of conditions. ${ }^{6,7,21-23}$ Previous studies in this regard mainly focused on heavy oil/bitumen viscosity diluted with heavy alkanes with carbon number larger than 5 where a single liquid phase is achieved because of the high solubility of such solvents. ${ }^{21-23}$ However, such heavy alkanes are found to be too expensive to be applied in oilfields (a single phase is also difficult to achieve under real field conditions) especially when they are in liquid states, while a vapor-liquid equilibrium with a lighter solvent such as propane is more commonly countered in practice. ${ }^{5,24-26}$ Thus, it is desirable to accurately predict the viscosity of light solvents-heavy oil/bitumen mixtures with a vapor-liquid equilibrium by using simple mixing rules if the prediction accuracy can be increased significantly and a generalization can be achieved. Also, water (it is frequently countered in processes such as SAGD, ${ }^{3}$ ES-SAGD, ${ }^{5}$ and wateralternating-gas $(W A G)^{8}$ ) effects on the viscosity of solvents-heavy oil/bitumen mixture cannot be ignored because its solubility in such a mixture can be high at elevated temperatures and obvious oil viscosity reduction can be induced under such conditions. ${ }^{7,8}$ Thus, it is of significance to include water in simple mixing rules to yield accurate viscosity prediction for solvents-heavy oil/bitumen-water mixtures and examine effects of solvents/water on the mixture viscosity under different conditions.

In this study, six widely used mixing rules are evaluated and compared to predict the viscosity for light solvents (i.e., methane, ethane, propane, $n$-butane, $n$-pentane, $\mathrm{N}_{2}$, and $\mathrm{CO}_{2}$ )-heavy oil/bitumen mixtures as a function of pressure at vapor-liquid equilibria in the temperature range of 287.9463.4 K. The effective density of dissolved gas solvents is for the first time successfully introduced into such mixing rules which is in the volume-based form. The Peng-Robinson equation of state (PR EOS) with modified alpha functions and binary interaction parameters (BIPs) is used to calculate the LV and ALV phase equilibria for solvents-heavy oil/bitumenwater mixtures, while the linear mixing rule is used for solvents-heavy oil/bitumen mixtures and water. Also, effects of different solvents on reducing the viscosity of heavy oil/ bitumen systems are thoroughly compared with and without consideration of solubility, while effects of water are systematically evaluated under different conditions.

\section{EXPERIMENTAL DATABASE}

In this study, measured viscosities of four different heavy oils/ bitumens and seven solvents (i.e., methane, ethane, propane, $n$ butane, $n$-pentane, $\mathrm{CO}_{2}$, and $\mathrm{N}_{2}$ ) are collected from the literature, while the physical properties of these heavy oils/ bitumens are tabulated in Table $1 .{ }^{20,27-29}$ The densities and viscosities of such heavy oils/bitumens have been regressed as a function of temperature and pressure, yielding AARDs within $1.0 \%$ and $8.4 \%$, respectively. ${ }^{20,27-29}$ Detailed information for the 258 measured viscosities for solvents-heavy oil/bitumen/ water systems ${ }^{19,29-34}$ can be found in Table 2 in a temperature range of $287.9-463.4 \mathrm{~K}$ and a pressure range of $0.46-10.94$ $\mathrm{MPa}$, respectively. The range of the measured viscosities for the corresponding mixtures is from 0.7 to $16300.0 \mathrm{mPa} \cdot \mathrm{s}$. Vapor phase always exists for the systems in Table 2 where the measured mixture viscosity data are summarized. For convenience, the aqueous phase which is mainly comprised of liquid water is denoted as "A"; the heavy oil/bitumen-rich liquid phase (i.e., oleic phase) which contains a large amount of both heavy oil/bitumen and solvents is denoted as "L"; and the vapor phase which is mainly composed of gaseous solvents and/or steam is denoted as "V". The LV equilibria can be formed when the aqueous phase disappears due to the fact that water is either dissolved into oleic phase or transformed to vapor phase.

\section{MATHEMATICAL FORMULATIONS}

3.1. PR EOS. Although an equation of state (EOS) cannot be directly used to predict viscosity, its calculation of oleic phase composition is needed for calculating the mixture viscosity associated with the mixing rules. ${ }^{19,21}$ PR EOS $^{35}$ has been widely used in the field of petroleum and chemical engineering, and it is written as follows:

$$
\begin{aligned}
& P=\frac{R T}{V-b}-\frac{a}{V(V+b)+b(V-b)} \\
& a=a_{\mathrm{c}} \alpha\left(T_{\mathrm{r}}, \omega\right) \\
& a_{\mathrm{c}}=\frac{0.457235 R^{2} T_{\mathrm{c}}^{2}}{P_{\mathrm{c}}} \\
& b=\frac{0.0777969 R T_{\mathrm{c}}}{P_{\mathrm{c}}}
\end{aligned}
$$

where $\alpha\left(T_{r}, \omega\right)$ is the alpha function, which is the function of both the reduced temperature $T_{\mathrm{r}}$ and the acentric factor $\omega, T$ is the temperature, $P$ is the pressure, $V$ is the molar volume, $R$ is the universal gas constant, $T_{\mathrm{c}}$ is the critical temperature, and $P_{\mathrm{c}}$ is the critical pressure.

A newly modified alpha function proposed by Chen and Yang, ${ }^{36}$ which is found to more accurately predict the vapor pressure for heavy hydrocarbon compounds by redefining the 


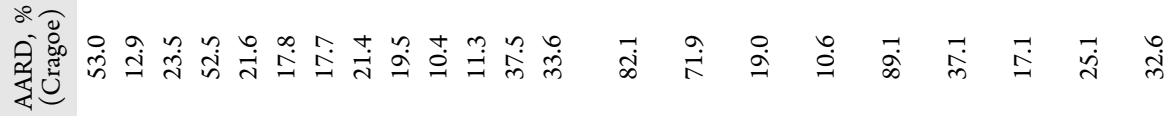

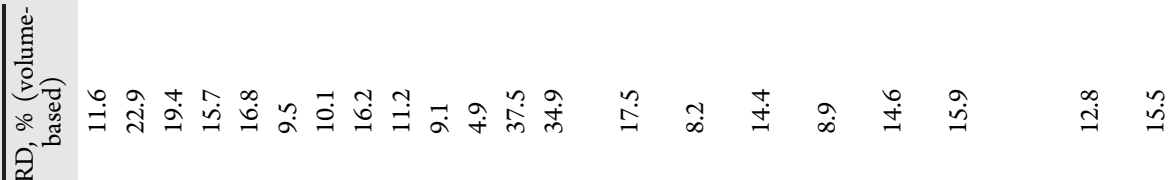

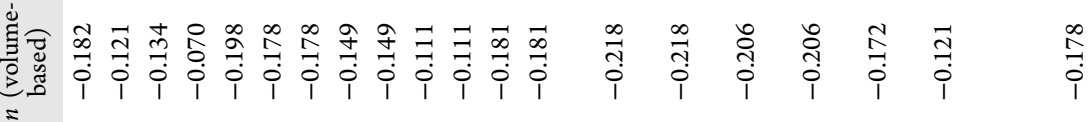
:.

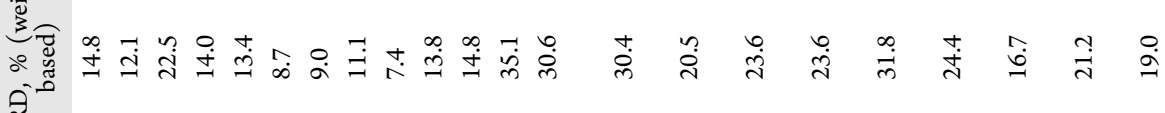

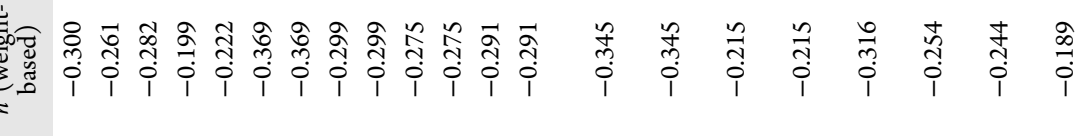

芶方ニ

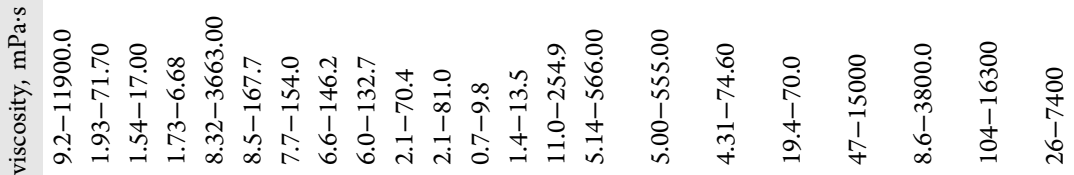

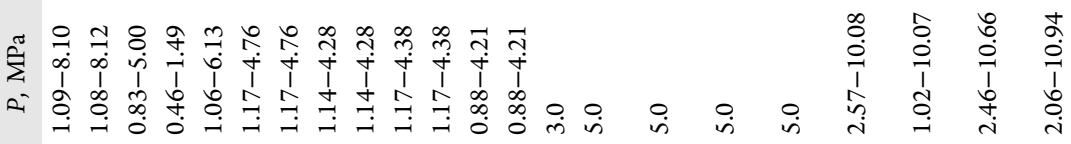

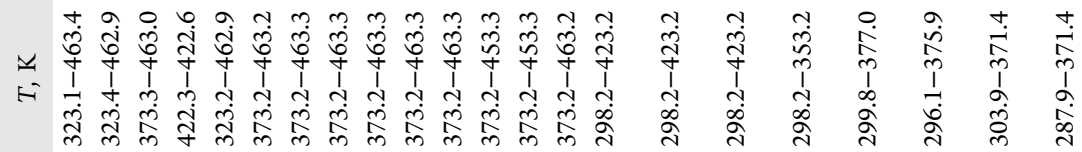

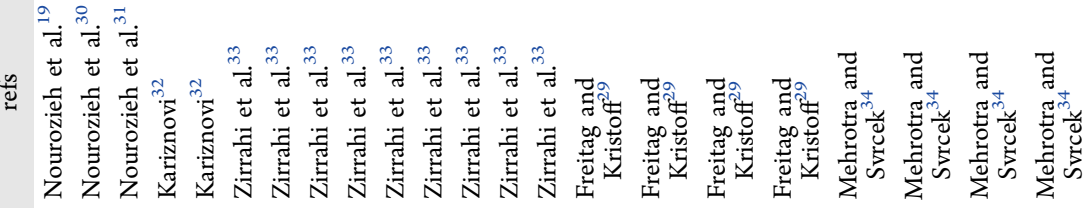

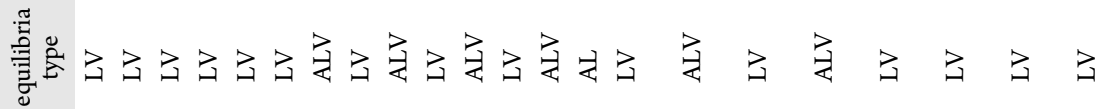

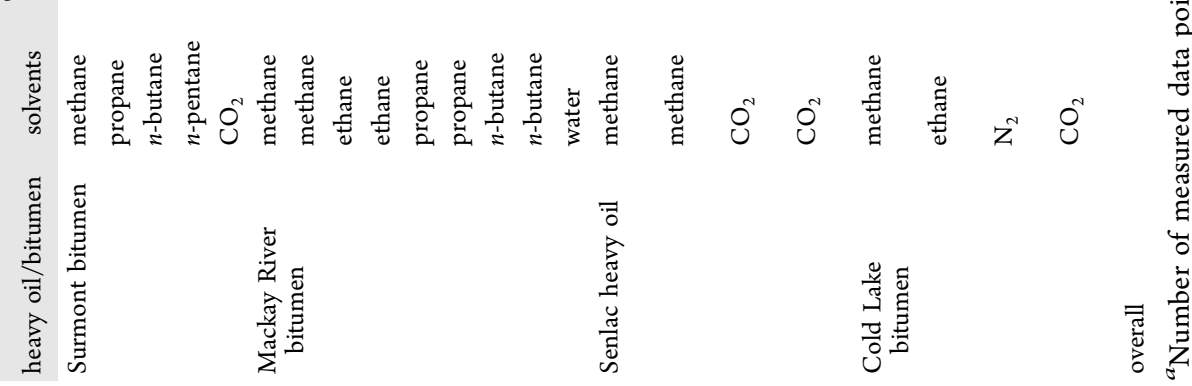


acentric factor at reduced temperature of 0.6 , is adopted for nonwater components in this study and expressed as follows:

$$
\begin{aligned}
& \alpha=\left\{\begin{array}{l}
\left(0.33730-0.26346 \omega+0.05297 \omega^{2}\right)\left(1-T_{\mathrm{r}}\right) \\
+1.01711 \ln \\
{\left[1+\left(-0.42587+1.16423 \omega-0.10857 \omega^{2}\right)\left(1-\sqrt{T_{\mathrm{r}}}\right)\right]^{2}}
\end{array}\right\}
\end{aligned}
$$

In addition, a new alpha function special for water has been developed for more accurately predicting the vapor pressure for water in a wide temperature range of $273.16-647.10 \mathrm{~K}^{37}$ With minor modifications, it can be expressed as follows: ${ }^{38}$

$$
\alpha_{\mathrm{H}_{2} \mathrm{O}}=\left[c_{1}+c_{2}\left(1-T_{\mathrm{rw}}\right)-c_{3}\left(1-T_{\mathrm{rw}}^{-1}\right)+c_{4}\left(1-T_{\mathrm{rw}}^{-2}\right)\right]^{2}
$$

where $T_{\mathrm{rw}}$ is the reduced temperature of water, $c_{1}=1.00000, c_{2}$ $=0.39222, c_{3}=0.07294$, and $c_{4}=0.00706$, respectively.

For mixtures, the conventional van der Waals mixing rule is used and expressed as follows:

$$
\begin{aligned}
& a=\sum_{i=1}^{n c} \sum_{j=1}^{n c} y_{i} y_{j}\left(a_{i} a_{j}\right)^{0.5}\left(1-\delta_{i j}\right) \\
& b=\sum_{i=1}^{n c} y_{i} b_{i}
\end{aligned}
$$

where $n c$ is the number of components of the mixture, $y_{i}$ and $y_{j}$ are the mole fractions of the $i$ th and $j$ th component in the mixture, respectively, and $\delta_{i j}$ is the BIP between the $i$ th and $j$ th component in the mixture.

3.2. Heavy Oil/Bitumen Characterization and BIPs. In this study, each heavy oil/bitumen is treated as a single pseudocomponent, while their properties are calculated using the existing correlations. ${ }^{39}$ The detailed properties of the four heavy oils/bitumens studied in this work are tabulated in Table 1. All of the properties for methane, ethane, propane, $n$-butane, $n$-pentane, toluene, $\mathrm{CO}_{2}$, and water are obtained from the CMG WinProp database ${ }^{40}$ except for their acentric factors. The BIPs for solvent-heavy oil/bitumen pairs (denoted as $\mathrm{BIP}_{\text {solvent-HO}}$ ) are tuned to match the measured saturation pressures or solvent solubilities in heavy oils/bitumens for all the solvents-heavy oil/bitumen systems listed in Table 2 . Such tuned BIP solvent-HO is directly used for calculating the phase equilibria for the corresponding solvents-heavy oil/ bitumen-water systems. All of the calculations regarding the acentric factors of different components/pseudocomponents and BIPs except for BIP $_{\text {solvent-HO }}$ can be found elsewhere. $^{38,41,42}$

In this study, the absolute average relative deviation (AARD) is used as the objective function to evaluate the prediction accuracy of the developed model in this work, which is expressed as follows:

$$
\operatorname{AARD}=\frac{1}{N} \sum_{i=1}^{N}\left|\frac{\mu_{i}^{\mathrm{cal}}-\mu_{i}^{\exp }}{\mu_{i}^{\exp }}\right| \times 100 \%
$$

where $N$ is the number of measured data points, $\mu_{i}^{\text {cal }}$ is the calculated oleic phase viscosity, and $\mu_{i}^{\exp }$ is the measured oleic phase viscosity. All of the calculations are performed with the MatLab software (Version 2012).

3.3. Viscosity Mixing Rules. 3.3.1. Solvents-Heavy Oil/ Bitumen Systems. In this study, six widely used mixing rules (i.e., Arrhenius', Cragoe's, Shu's, Lobe's, double log, and power law mixing rules) are evaluated and compared to predict the liquid phase viscosity for solvents-heavy oil/bitumen mixtures at vapor-liquid equilibria. These mixing rules are written respectively as follows:

(1) Arrhenius' mixing rule: ${ }^{43}$

$$
\mu_{\mathrm{m}}=\mu_{\mathrm{s}}^{x_{\mathrm{s}}} \mu_{\mathrm{b}}^{1-x_{\mathrm{s}}}
$$

where $\mu_{\mathrm{m}}$ is the viscosity of solvents-heavy oil/bitumen mixtures, $x_{\mathrm{s}}$ is the solvent molar fraction, and $\mu_{\mathrm{s}}$ and $\mu_{\mathrm{b}}$ are the dynamic viscosities of solvent and heavy oil/bitumen, respectively. It can also be expressed in the log-format as follows:

$$
\ln \mu_{\mathrm{m}}=x_{\mathrm{s}} \ln \mu_{\mathrm{s}}+\left(1-x_{\mathrm{s}}\right) \ln \mu_{\mathrm{b}}
$$

(2) Power law mixing rule: ${ }^{44}$

$$
\mu_{\mathrm{m}}=\left[x_{\mathrm{s}} \mu_{\mathrm{s}}^{n}+\left(1-x_{\mathrm{s}}\right) \mu_{\mathrm{b}}^{n}\right]^{1 / n}
$$

where $n$ is an adjustable parameter. The power law model is developed based on the Kendall model, ${ }^{44}$ where the mixture viscosity is directly dependent on the molar fraction.

(3) Cragoe's mixing rule: ${ }^{45}$

$$
\frac{1}{\ln \left(2000 \mu_{\mathrm{m}}\right)}=\frac{w_{\mathrm{s}}}{\ln \left(2000 \mu_{\mathrm{s}}\right)}+\frac{1-w_{\mathrm{s}}}{\ln \left(2000 \mu_{\mathrm{b}}\right)}
$$

where $w_{\mathrm{s}}$ is the solvent weight fraction.

(4) Lobe's mixing rule: ${ }^{46}$

$$
\nu_{\mathrm{m}}=\varphi_{\mathrm{s}} \nu_{\mathrm{s}} \exp \left(\eta_{\mathrm{b}} \varphi_{\mathrm{b}}\right)+\varphi_{\mathrm{b}} \nu_{\mathrm{b}} \exp \left(\eta_{\mathrm{s}} \varphi_{\mathrm{s}}\right)
$$

where $\nu_{\mathrm{m}}$ is the kinematic viscosity of solvents-heavy oil/ bitumen mixtures, $\varphi_{\mathrm{s}}$ and $\varphi_{\mathrm{b}}$ are the solvent and heavy oil/ bitumen volume fractions under ambient conditions, and $\nu_{\mathrm{s}}$ and $\nu_{\mathrm{b}}$ are the kinematic viscosities of solvent and heavy oil/ bitumen, respectively. $\eta_{\mathrm{b}}$ and $\eta_{\mathrm{s}}$ are expressed as follows:

$$
\begin{aligned}
& \eta_{\mathrm{b}}=0.27 \ln \left(\frac{\nu_{\mathrm{b}}}{\nu_{\mathrm{s}}}\right)+\left[1.3 \ln \left(\frac{\nu_{\mathrm{b}}}{\nu_{\mathrm{s}}}\right)\right]^{1 / 2} \\
& \eta_{\mathrm{s}}=-1.7 \ln \left(\frac{\nu_{\mathrm{b}}}{\nu_{\mathrm{s}}}\right)
\end{aligned}
$$

(5) Shu's mixing rule: ${ }^{47}$

$$
\ln \mu_{\mathrm{m}}=\left(1-\frac{\theta \varphi_{\mathrm{b}}}{\theta \varphi_{\mathrm{b}}+\varphi_{\mathrm{s}}}\right) \ln \mu_{\mathrm{s}}+\left(\frac{\theta \varphi_{\mathrm{b}}}{\theta \varphi_{\mathrm{b}}+\varphi_{\mathrm{s}}}\right) \ln \mu_{\mathrm{b}}
$$

where $\theta$ is an adjustable parameter in the range of 0 to 1 , while it is expressed as follows:

$$
\theta=\frac{17.04\left(\rho_{\mathrm{b}}-\rho_{\mathrm{s}}\right)^{0.5237} \rho_{\mathrm{b}}^{3.2745} \rho_{\mathrm{s}}^{1.6316}}{\ln \left(\frac{\mu_{\mathrm{b}}}{\mu_{\mathrm{s}}}\right)}
$$

where $\rho_{\mathrm{b}}$ and $\rho_{\mathrm{s}}$ are the heavy oil/bitumen and solvent densities, respectively.

(6) Double-log mixing rule: ${ }^{48}$

$$
\begin{aligned}
\ln \left[\ln \left(\mu_{\mathrm{m}}+1\right)\right]= & w_{\mathrm{s}} \ln \left[\ln \left(\mu_{\mathrm{s}}+1\right)\right]+\left(1-w_{\mathrm{s}}\right) \\
& \ln \left[\ln \left(\mu_{\mathrm{b}}+1\right)\right]
\end{aligned}
$$


Table 3. Comparisons among Different Mixing Rules for the Predicted Viscosities of Solvents-Surmont Bitumen Mixtures

\begin{tabular}{|c|c|c|c|c|}
\hline \multirow[b]{3}{*}{ mixing rule } & \multicolumn{4}{|c|}{ AARD, $\%$} \\
\hline & \multicolumn{3}{|c|}{ volume-based } & \multirow[b]{2}{*}{ molar-based } \\
\hline & weight-based & effective density & real density & \\
\hline Arrhenius & 306.5 & $157.9^{a}$ & $86.5^{a}$ & 73.4 \\
\hline Cragoe & 29.7 & 45.9 & 98.2 & 94.9 \\
\hline power-law & $22.1(n=-0.262)$ & $27.9(n=-0.184)$ & $74.3(n=0.149)$ & $49.3(n=0.141)$ \\
\hline double log & 40.3 & & & \\
\hline Lobe & & 72.2 & 93.4 & \\
\hline Shu & & 55.6 & 93.6 & \\
\hline
\end{tabular}

${ }^{a}$ A lower AARD with real density than that with effective density does not mean using real density is better because all of the predicted viscosity with real density is much smaller than the measured one, and thus an overall AARD close to $100 \%$ is yielded. On the contrary, the high AARD (i.e., $157.9 \%$ ) with effective density is due to very high AARDs (it can be as high as $1800 \%$ ) for a very small part of measured data (i.e., high viscosity data for methane $/ \mathrm{CO}_{2}$-bitumen mixtures), while most of the predictions with effective density are good.

3.3.2. Hydrocarbon-Water Systems. Glandt and Chap$\operatorname{man}^{6}$ recommended that the linear mixing rule be used for heavy oil/bitumens-water systems, and it is used in this study and expressed as follows for the systems in this work:

$$
\mu_{\mathrm{m}}=x_{\mathrm{HC}} \mu_{\mathrm{HC}}+x_{\mathrm{w}} \mu_{\mathrm{w}}
$$

where $\mu_{\mathrm{m}}$ is the viscosity of solvents-heavy oil/bitumen-water mixtures, $x_{\mathrm{HC}}$ and $\mu_{\mathrm{HC}}$ are the molar fraction and viscosity of solvents-heavy oil/bitumen mixtures, and $x_{\mathrm{w}}$ and $\mu_{\mathrm{w}}$ are the molar fraction and viscosity of water, respectively.

All of the viscosity and real density data of pure solvents and water under different conditions are taken from the NIST Chemistry WebBook. ${ }^{49}$

3.4. Effective Density. The density of a liquid mixture with a dissolved gas can be calculated with the following mixing rule with the assumption of no volume change on mixing: ${ }^{19}$

$$
\rho_{\mathrm{m}}=1 /\left(\frac{w_{\mathrm{s}}}{\rho_{\mathrm{s}}^{\text {eff }}}+\frac{w_{\mathrm{b}}}{\rho_{\mathrm{b}}^{\text {eff }}}+\frac{w_{\text {water }}}{\rho_{\text {water }}^{\text {eff }}}\right)
$$

where $\rho_{\mathrm{m}}$ is the density of the liquid mixture, $w_{\mathrm{s}}, w_{\mathrm{b}}$, and $w_{\text {water }}$ are the weight fractions of dissolved gas, heavy oil/bitumen, and water, respectively, and $\rho_{\mathrm{s}}^{\text {eff }}, \rho_{\mathrm{b}}^{\text {eff }}$, and $\rho_{\text {water }}^{\text {eff }}$ are the effective densities (rather than real densities) of dissolved gas, heavy oil/bitumen, and water, respectively. It is worthwhile noting that the effective densities of heavy oil/bitumen and water are equal to their real densities if they lie in the liquid state.

Both Tharanivasan et al. ${ }^{50}$ and Saryazdi ${ }^{51}$ have developed correlations to calculate the effective densities for $n$-alkanes from methane to $n$-heptane (i.e., the equivalent density of a dissolved gas in heavy oil/bitumen) with the following format:

$$
\rho_{\mathrm{s}}^{\text {eff }}=a_{1}+a_{2} T+\left(a_{3}+a_{4} T\right) P
$$

where $a_{1}, a_{2}, a_{3}$, and $a_{4}$ are coefficients to be regressed, while the correlations developed by Saryazdi ${ }^{51}$ are used for $n$-alkanes in this study. Note that the pressure and temperature in eq 15 have the units of $\mathrm{K}$ and $\mathrm{MPa}$, respectively. Such correlations are found to well reproduce the density for bitumen diluted with solvents.

For calculating the effective density of $\mathrm{CO}_{2}$, Tharanivasan et al. $^{50}$ developed a correlation expressed as follows:

$$
\begin{aligned}
\rho_{\mathrm{CO}_{2}}^{\text {eff }}= & 2334.9 \exp (-0.003157 T) \exp \left\{4.12 \times 10^{-4} \mathrm{P}\right. \\
& \left.+(-0.3233+0.001897 T)\left[1-\exp \left(-1.37 \times 10^{-2} P\right)\right]\right\}
\end{aligned}
$$

where $\rho_{\mathrm{CO}_{2}}^{\text {eff }}$ is the effective density of $\mathrm{CO}_{2}, \mathrm{~kg} / \mathrm{m}^{3}$, and temperature and pressure have the units of $\mathrm{K}$ and $\mathrm{MPa}$, respectively.

\section{RESULTS AND DISCUSSION}

4.1. Prediction Accuracy. Table 3 shows the AARDs with different mixing rules for the predicted viscosities for solventsSurmont bitumen mixtures (measured data are taken from the literature ${ }^{19-32}$ ). Note that the weight-based, volume-based,

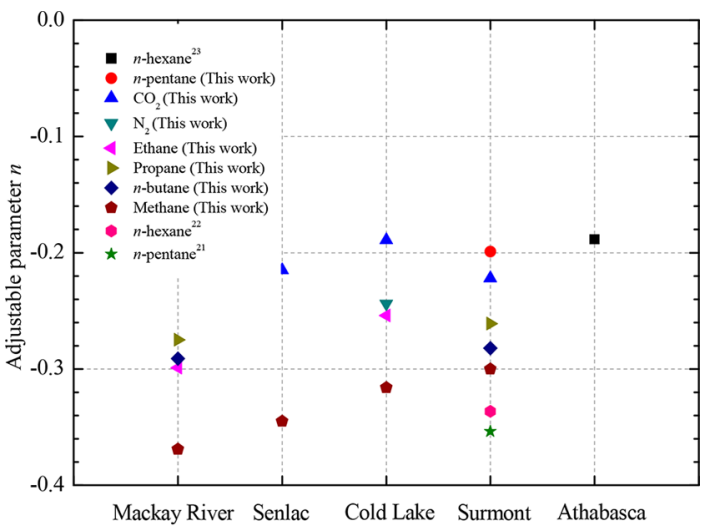

(a)

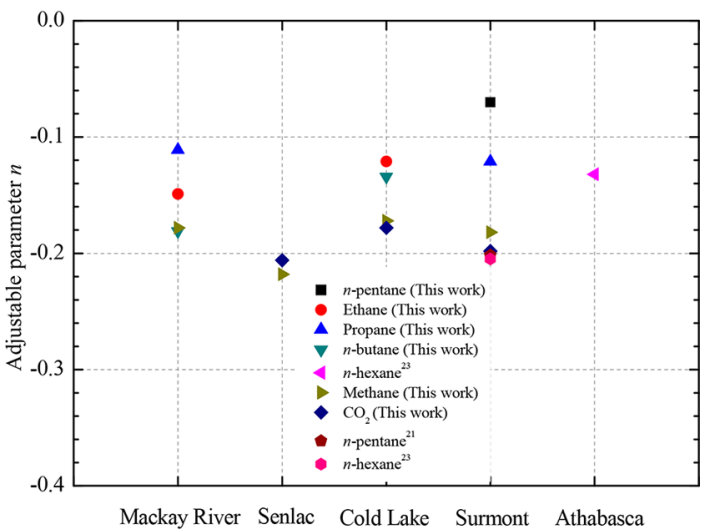

(b)

Figure 1. Adjustable parameter $n$ in the power law mixing rule in (a) weight-based format and (b) volume-based format. 


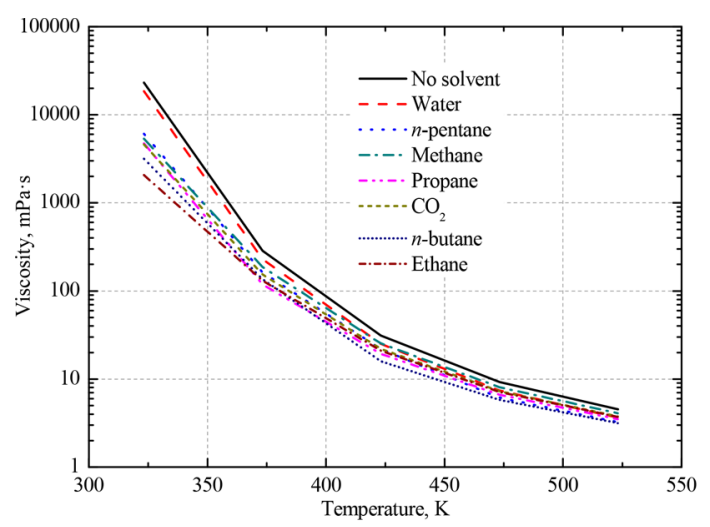

(a)

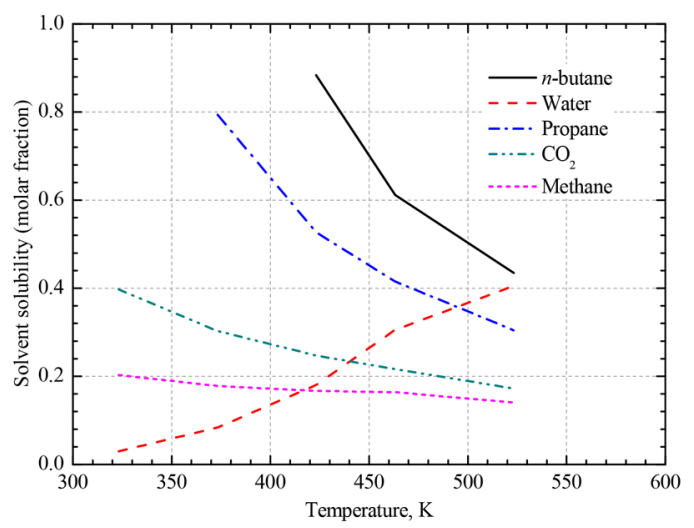

(b)

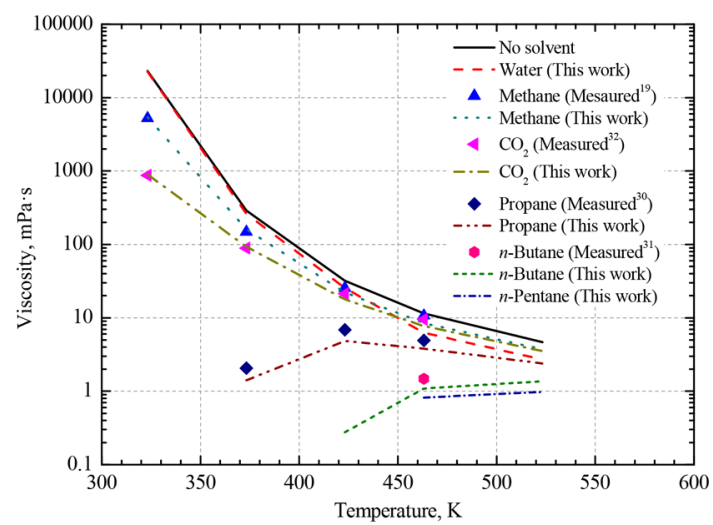

(c)

Figure 2. (a) Viscosities with temperature for Surmont bitumen with dissolution of $20 \mathrm{~mol} \%$ different solvents at $4 \mathrm{MPa}$; (b) solvent solubility (i.e., the solvent molar fraction in a solvents-heavy oil/ bitumen mixture) in Surmont bitumen with temperature at $4 \mathrm{MPa}$; and (c) viscosities with temperature for Surmont bitumen at $4 \mathrm{MPa}$ in real case. It should be noted that, in Figure 2a, 20 mol \% solvent may not be valid in real cases as it is an imaginary value for comparison among solvents when solubility is not considered.

and molar-based format are all evaluated for the Arrhenius's, Cragoe's, and power law mixing rules, respectively. As can be seen from the comparison, the weight-based and volume-based power law, and weight-based Cragoe's mixing rules are obviously better than others with AARDs lower than $30.0 \%$. The double-log and volume-based Cragoe's mixing rule are worse than but next to the aforementioned mixing rules, while some of the mixing rules such as the Arrhenius's mixing rule yield very large deviations. It is worthwhile noting that the volume-based mixing rules with effective density for dissolved gas are much more accurate than those with real densities. This is also true for density predictions when choosing effective density or real density for dissolved gas(es) to predict the density for solvents-heavy oil/bitumen mixtures. ${ }^{19}$ This indicates that the dissolved gas in heavy oil/bitumen should be treated as liquid to some extent.

It is shown in the literature that both the weight-based and volume-based power law mixing rules perform well for predicting viscosities for $n$-pentane $/ n$-hexane-bitumen mixtures where the solvents lie in the liquid state. ${ }^{21-23}$ The adjustable parameter $n$ in volume-based power law mixing rule calculated by Nourozieh et al. ${ }^{22}$ and Gao et al. ${ }^{23}$ for $n$-hexane diluted bitumens is -0.205 and -0.132 , respectively, while the $n$ calculated in this work using effective and real density is found to be -0.184 and +0.149 , respectively. The adjustable parameter with effective density in this work can be comparable to those in the literature, ${ }^{22,23}$ whereas the one with real density is greatly deviated from those in the literature. $^{22,23}$ This further illustrates that effective density rather than real density of dissolved gases should be used in the volume-based mixing rule. Also, the $n$ in weight-based power law mixing rule calculated by Nourozieh et al. ${ }^{22}$ and Gao et al. $^{23}$ for $n$-hexane diluted bitumens is -0.337 and -0.189 , respectively, each of which is also comparable to the calculated one (i.e., -0.262) in this work. Regarding the Cragoe's mixing rule, both Nourozieh's work ${ }^{21,22}$ and Gao's work ${ }^{23}$ indicate that the volume-based Gragoe's mixing rule is accurate for $n$ pentane $/ n$-hexane $/ n$-octane-bitumen mixtures. Nourozieth's work $^{21,22}$ shows that the weight-based Gragoe's mixing rule is not accurate, whereas Gao's work ${ }^{23}$ exhibits that it is accurate for $n$-pentane $/ n$-hexane $/ n$-octane-bitumen mixtures. Similar to Gao's work, ${ }^{23}$ the weight-based Gragoe's mixing rule also performs well in this work with an AARD of $29.7 \%$.

Table 2 shows the detailed comparisons among the weightbased and volume-based power law mixing rules and weightbased Cragoe's mixing rule. The adjustable parameters in the power law mixing rule are tuned for specific solvents rather than for a certain heavy oil/bitumen as indicated in Table 3. Overall, the weight-based Cragoe's mixing rule is accurate with an AARD of $32.6 \%$ except that it yields a larger AARD of up to $80.0 \%$ for methane-heavy oil/bitumens mixtures. Both the volume-based and weight-based power law mixing rules are much better than the weight-based Cragoe's mixing rule, whereas they are weaker than the weight-based Cragoe's mixing rule with respect to model generalization due to the tunable parameter. The volume-based power law mixing rule is better than the weight-based one, illustrating that effective density of dissolved gases should be used not only for density prediction but also for viscosity prediction for solvents-heavy oil/bitumen mixtures. In the subsequent section, the volumebased power law mixing rule is used to calculate the viscosity for a solvents-heavy oil/bitumen-water mixture to examine effects of solvents and water under different conditions.

As shown in Figure 1, overall, the adjustable parameter $n$ for weight-based and volume-based power law mixing rules are in the range of -0.4 to -0.2 and -0.2 to -0.1 , respectively. A constant value for $n$ can be used for a specific solvent as they are not varied significantly from heavy oil/bitumen to heavy oil/bitumen. In this study, the average value of the parameter $n$ for a specific solvent is recommended when no viscosity data are available to tune it. The parameter $n$ is calculated to be 
Table 4. Calculated Viscosities of Methane-Mackay River Bitumen-Water Systems with Water Molar Fraction in Feed ${ }^{a}$

\begin{tabular}{|c|c|c|c|c|c|c|c|c|c|}
\hline \multirow[b]{3}{*}{ temperature, $\mathrm{K}$} & \multirow[b]{3}{*}{ system pressure, $\mathrm{MPa}$} & \multicolumn{8}{|c|}{ viscosity, $\mathrm{mPa} \cdot \mathrm{s}$} \\
\hline & & \multicolumn{8}{|c|}{ molar fraction of water in feed } \\
\hline & & 0.00 & 0.02 & 0.04 & 0.06 & 0.08 & 0.12 & 0.16 & 0.50 \\
\hline \multirow[t]{4}{*}{373.15} & 1.69 & 189.7 & 187.2 & 185.8 & 184.0 & 184.0 & 184.0 & 184.0 & 184.0 \\
\hline & 2.48 & 175.9 & 172.3 & 169.9 & 169.6 & 169.6 & 169.6 & 169.6 & 169.6 \\
\hline & 3.17 & 157.3 & 154.2 & 151.3 & 151.3 & 151.3 & 151.3 & 151.3 & 151.3 \\
\hline & 4.41 & 135.3 & 133.8 & 129.5 & 129.5 & 129.5 & 129.5 & 129.5 & 129.5 \\
\hline \multirow[t]{4}{*}{423.15} & 1.17 & 24.7 & 24.6 & 24.5 & 24.4 & 24.3 & 24.2 & 24.0 & 23.3 \\
\hline & 1.93 & 23.7 & 23.5 & 23.4 & 23.3 & 23.2 & 22.9 & 22.7 & 22.2 \\
\hline & 2.66 & 22.7 & 22.5 & 22.3 & 22.1 & 22.0 & 21.6 & 21.3 & 21.2 \\
\hline & 3.93 & 21.2 & 20.9 & 20.6 & 20.4 & 20.1 & 19.6 & 19.6 & 19.6 \\
\hline \multirow[t]{4}{*}{463.15} & 1.86 & 9.2 & 9.2 & 9.1 & 9.1 & 9.0 & 9.0 & 8.9 & 8.3 \\
\hline & 2.69 & 8.9 & 8.9 & 8.8 & 8.7 & 8.7 & 8.6 & 8.5 & 8.0 \\
\hline & 3.72 & 8.5 & 8.5 & 8.4 & 8.3 & 8.3 & 8.1 & 8.0 & 7.6 \\
\hline & 4.76 & 8.3 & 8.3 & 8.2 & 8.1 & 8.0 & 7.9 & 7.7 & 7.3 \\
\hline
\end{tabular}

${ }^{a}$ The italic and bold fonts represent ALV equilibria, and the regular fonts denote LV equilibria.

Table 5. Calculated Viscosities of Propane-Mackay River Bitumen-Water Systems with Water Molar Fraction in Feed ${ }^{a}$

\begin{tabular}{|c|c|c|c|c|c|c|c|c|c|}
\hline \multirow[b]{3}{*}{ temperature, $\mathrm{K}$} & \multirow[b]{3}{*}{ system pressure, $\mathrm{MPa}$} & \multicolumn{8}{|c|}{ viscosity, $\mathrm{mPa} \cdot \mathrm{s}$} \\
\hline & & \multicolumn{8}{|c|}{ molar fraction of water in feed } \\
\hline & & 0.00 & 0.02 & 0.04 & 0.06 & 0.08 & 0.12 & 0.16 & 0.50 \\
\hline \multirow[t]{4}{*}{373.15} & 1.17 & 77.8 & 78.6 & 79.4 & 80.4 & 81.5 & 81.5 & 81.5 & 81.5 \\
\hline & 2.14 & 32.2 & 33.3 & 33.4 & 33.6 & 33.6 & 33.6 & 33.6 & 33.6 \\
\hline & 3.17 & 5.6 & 5.8 & 6.0 & 6.0 & 6.0 & 6.0 & 6.0 & 6.0 \\
\hline & 4.21 & 1.7 & 1.8 & 1.9 & 1.9 & 1.9 & 1.9 & 1.9 & 1.9 \\
\hline \multirow[t]{4}{*}{423.15} & 1.24 & 15.4 & 15.5 & 15.6 & 15.7 & 15.9 & 16.1 & 16.3 & 17.4 \\
\hline & 2.14 & 11.4 & 11.5 & 11.5 & 11.7 & 11.8 & 12.0 & 12.2 & 12.4 \\
\hline & 3.31 & 7.3 & 7.3 & 7.4 & 7.4 & 7.5 & 7.7 & 7.7 & 7.7 \\
\hline & 4.21 & 4.9 & 4.9 & 4.9 & 5.0 & 5.1 & 5.1 & 5.1 & 5.1 \\
\hline \multirow[t]{4}{*}{463.15} & 1.69 & 6.3 & 6.4 & 6.4 & 6.4 & 6.4 & 6.5 & 6.6 & 7.5 \\
\hline & 2.52 & 5.1 & 5.1 & 5.1 & 5.2 & 5.2 & 5.3 & 5.4 & 6.0 \\
\hline & 3.41 & 4.1 & 4.1 & 4.2 & 4.2 & 4.2 & 4.3 & 4.4 & 4.8 \\
\hline & 4.38 & 3.2 & 3.2 & 3.2 & 3.2 & 3.3 & 3.4 & 3.4 & 3.6 \\
\hline
\end{tabular}

${ }^{a_{T}}$ The italic and bold fonts represent ALV equilibria, and the regular fonts denote LV equilibria.

$-0.333,-0.268,-0.277,-0.287$, and -0.209 , respectively, for methane, ethane, propane, $n$-butane, and $\mathrm{CO}_{2}$ associated with the weight-based power law mixing rule, while it is calculated to be $-0.188,-0.116,-0.135,-0.158$, and -0.194 , respectively, for the volume-based power law mixing rule.

4.2. Effect of Solvents. Comparisons are conducted among the effects of different solvents on diluting heavy oil/ bitumen. As shown in Figure 2a, overall, when $20 \mathrm{~mol} \%$ solvent is dissolved in the Surmont bitumen at $4 \mathrm{MPa}$, a heavier solvent leads to a lower viscosity for solvent-bitumen mixtures. Water is found to have a weaker ability than the other solvents to dilute the bitumen, while the difference is decreased with temperature. At high temperatures, water is found to outperform methane in diluting bitumen without consideration of solubility. It should be noted that, in Figure 2 a, 20 mol \% solvent may not be valid in the real case ${ }^{19,31,32}$ as it is an arbitrary value for comparison among solvents when solubility is not considered. Experimentally, asphaltene precipitation has not been identified in these cases due to the small amount of the dissolved solvent in the heavy oils/ bitumens (e.g., the weight fractions of methane, ethane, and propane are only measured to be $0.0074,0.0137$, and 0.0200 , respectively). ${ }^{32,48}$ As such, the mixture of solvent(s)-heavy $\mathrm{oil} / \mathrm{bitumen}$ is in a state of steady single liquid phase. As shown in Figure $2 b$, all the solvents show a decreasing solubility in bitumen with temperature, while a heavier solvent exhibits a higher solubility. Contrary to such solvents, water is found to show an obvious increasing solubility with respect to an increase in temperature. Thus, in real cases, the viscosity of a bitumen-water mixture can be lower than those of methanebitumen and $\mathrm{CO}_{2}$-bitumen mixtures at high temperatures (see Figure 2c). It is expected that the viscosity of a bitumenwater mixture can be even lower than that of an $n$ pentane-bitumen mixture at extremely high temperatures. A heavier solvent has a higher diluting ability in the same amount of dissolution, and it also has a higher solubility in bitumen. As such, the bitumen diluted with a heavier solvent exhibits a lower viscosity under the same conditions. Note that the viscosity of the solvents-bitumen mixture may show an increasing trend with temperature under certain conditions due to the fact its solubility is decreased with temperature (see Figure 2c). In addition, all of the calculation procedures for the contents in Figure $2 c$ have been validated with literature data in Section 4.1. Physically, effects of different solvents in diluting heavy oil/bitumen can be compared by performing experiments at high temperatures with consideration of solvent solubility. ${ }^{19,31,32}$ The scientific findings from this study are consistent with those documented elsewhere. ${ }^{19,32}$ 


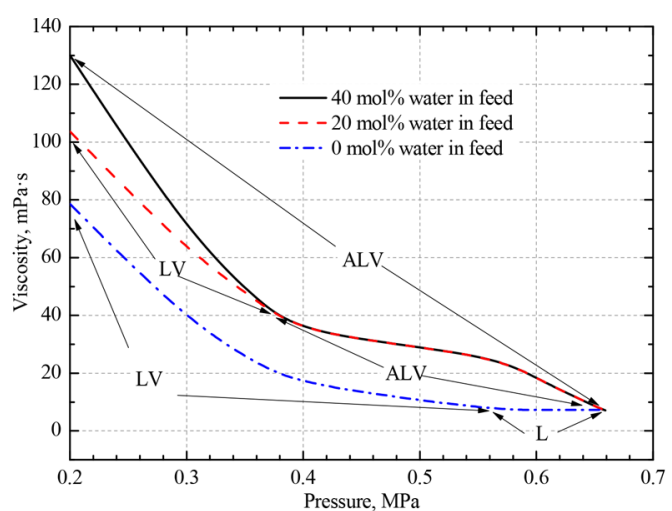

(a)

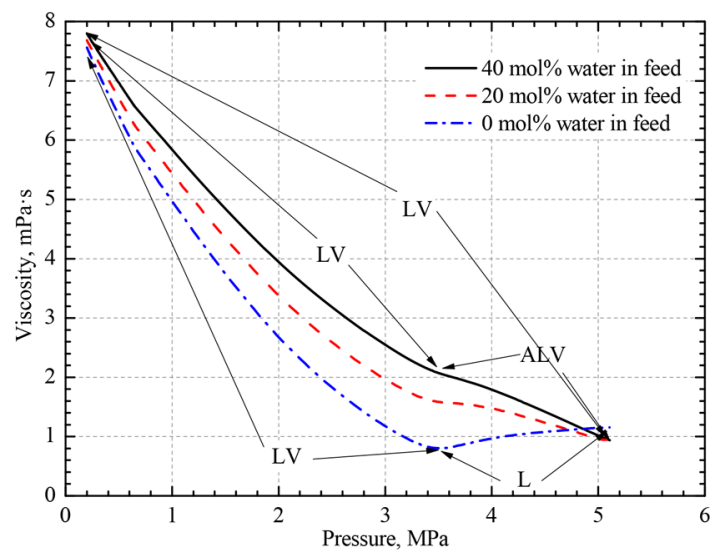

(b)

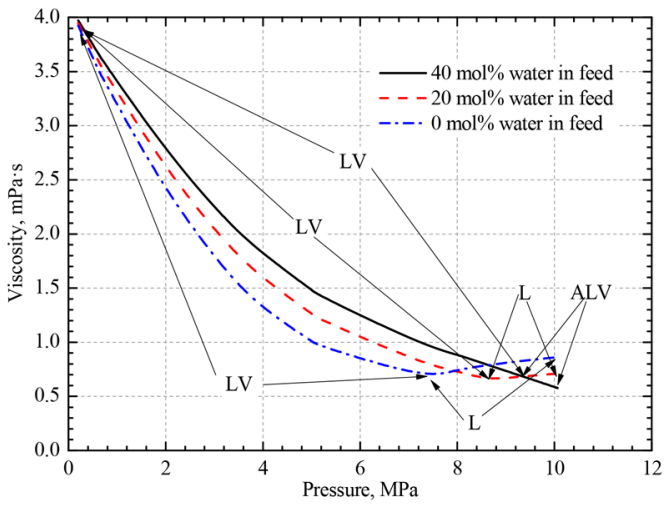

(c)

Figure 3. Viscosities of three different feeds $\left(x_{\mathrm{b}}: x_{\mathrm{s}}=1: 3\right.$ in molar fraction, while solvent used is $n$-pentane) at temperatures of (a) 373 , (b) 473 , and (c) $523 \mathrm{~K}$, respectively.

4.3. Effect of Water. As shown in Table 4, the viscosities of methane-Mackay River bitumen-water mixtures (see the column with 0.50 as the water molar fraction in feed) are lower than those of methane-Mackay River bitumen mixtures (see the column with 0.00 as the water molar fraction in feed), though the addition of water reduces the methane solubility in bitumen. ${ }^{38}$ This is because the water itself has a high ability to dilute bitumen without consideration of solubility and also it has high solubility at high temperatures. It is found that, at a given temperature and pressure, the viscosity of methanebitumen mixture is decreased with water molar fraction in feed at LV equilibria (see the regular fonts in Table 4) but keeps unchanged at ALV equilibria (see the italic and bold fonts in Table 4). This is because at LV equilibria and with an increasing water molar fraction in feed, more water is dissolved into bitumen to dilute it as its partial pressure is also increased. At ALV equilibria, the water molar fraction in feed exerts no effects on the phase equilibria, and thus it does not impose an impact on the mixture viscosity. ${ }^{38}$

As shown in Table 5, the viscosities of propane-Mackay River bitumen-water mixtures (see the column with 0.50 as the water molar fraction in feed) are higher than those of propane-Mackay River bitumen mixtures (see the column with 0.00 as the water molar fraction in feed). This is because the addition of water can significantly reduce the propane dissolution in bitumen and water has a lower ability to dilute bitumen compared with propane without consideration of solubility. At a given temperature and pressure, the viscosity of propane-bitumen mixture is increased with water molar fraction in feed at LV equilibria (see the regular fonts in Table 5) but keeps unchanged at ALV equilibria (see the italic and bold fonts in Table 5). This is because, at LV equilibria and with an increasing water molar fraction in feed, less propane is dissolved into bitumen to dilute it as its partial pressure is also decreased. Similar to methane-bitumen mixtures, at ALV equilibria, the water molar fraction in feed exerts no effects on the phase equilibria, and thus it does not impose an impact on the mixture viscosity.

As shown in Figure 3, the viscosity of $n$-pentane-Surmont bitumen mixture overall exhibits a decreasing trend with pressure at a given temperature, while more solvents are dissolved into the bitumen with pressure. The decrease of viscosity becomes slower with pressure at LV equilibria. The decreasing trend of the mixture viscosity is steeper at ALV equilibria than at LV equilibria due to the fact $n$-pentane dissolution in bitumen is quicker with pressure at ALV equilibria than at LV equilibria. ${ }^{38}$ The mixture viscosity is increased with pressure in a single liquid phase (i.e., L phase), while this pattern is also observed for pure heavy oils. ${ }^{20}$ The mixture viscosity is increased with water molar fraction in feed at LV equilibria under the same temperatures and pressures. This is because the addition of water reduces the $n$-pentane dissolution in bitumen significantly at LV equilibria, while water has a lower capacity to dilute bitumen than $n$-pentane without consideration of solubility. At ALV equilibria, however, the water molar fraction in feed exerts no effects on the phase equilibria, and thus it does not impose an impact on the mixture viscosity (see Figure 3a). Although the viscosity decreasing pattern is varied with water molar fraction in feed, different feeds can achieve viscosities close to each other at a certain point.

\section{CONCLUSIONS}

In this study, a new and pragmatic technique has been developed to accurately quantify the viscosity for light solvents-heavy oil/bitumen-water systems as a function of pressure in a temperature range of $287.9-463.4 \mathrm{~K}$ by using the PR EOS together with modified alpha functions and BIP correlations as well as newly developed mixing rules. Effective density for dissolved gas is for the first time successfully introduced into the volume-based viscosity mixing rules, while effects of solvents especially water on the mixture viscosity under different conditions are examined. Detailed findings are summarized as follows: 
(1) Among the six viscosity mixing rules for solvents-heavy oil/bitumen mixtures examined in this study, the volume-based power law takes the first place with an AARD of $15.5 \%$, the weight-based power law ranks the second with an AARD of $19.0 \%$, while the weight-based Cragoe's mixing rule takes the third place with an AARD of $32.6 \%$. It is found that the effective density rather than real density of dissolved gas should be used for all of the volume-based mixing rules. Overall, the adjustable parameter $n$ for weight-based and volume-based power law mixing rule are in the range of -0.4 to -0.2 and -0.2 to -0.1 , respectively. The recommended parameter $n$ is found to be $-0.333,-0.268,-0.277,-0.287$, and -0.209 , respectively, for methane, ethane, propane, $n$ butane, and $\mathrm{CO}_{2}$ for the weight-based power law, while it takes $-0.188,-0.116,-0.135,-0.158$, and -0.194 , respectively, for the volume-based power law mixing rule.

(2) It is found that a heavier solvent generally exhibits a higher ability to dilute heavy oil/bitumen in the same amount of solvent dissolution, while water can have a similar ability at high temperatures. The ability of water to dilute heavy oil/bitumen can outperform methane and $\mathrm{CO}_{2}$ at higher temperatures due to its much higher dissolution.

(3) Addition of water can either reduce or enhance the viscosity of a solvents-heavy oil/bitumen mixture, depending on the ability of solvent and water to dilute heavy oil/bitumen without consideration of solubility and effects of water on the solvent dissolution. Water molar fraction in feed can exert an effect on the mixture viscosity at $\mathrm{LV}$ equilibria through influencing the solvent dissolution, but it cannot impose an impact on the mixture viscosity at ALV equilibria. The mixture viscosity decreases more quickly at ALV equilibria than at LV equilibria with pressure because the solvent dissolution is quicker at ALV equilibria.

\section{AUTHOR INFORMATION}

\section{Corresponding Author}

*Phone: 1-306-337-2660. Fax: 1-306-585-4855. E-mail: tony. yang@uregina.ca.

\section{ORCID}

Xiaoli Li: 0000-0003-2989-1583

Daoyong Yang: 0000-0001-8820-6625

Notes

The authors declare no competing financial interest.

\section{ACKNOWLEDGMENTS}

The authors acknowledge a Discovery Development Grant, a Discovery Grant, and a Collaborative Research and Development (CRD) Grant from the Natural Sciences and Engineering Research Council of Canada (NSERC) to D. Yang and EHR Enhanced Hydrocarbon Recovery Inc. for financial support.

\section{NOTATIONS}

$a=$ attraction parameter in PR EOS

$a_{i}=$ attraction parameter of component $i$

$a_{j}=$ attraction parameter of component $j$

$b=$ van der Waals volume, $\mathrm{m}^{3} / \mathrm{kmol}$

$b_{i}=$ van der Waals volume of component $i, \mathrm{~m}^{3} / \mathrm{kmol}$

$\mathrm{BIP}_{\text {solvent-HO }}=\mathrm{BIP}$ between solvent and heavy oil/bitumen
$N=$ number of measured data points

$n=$ adjustable parameter in the power law mixing rule

$P=$ pressure, $\mathrm{MPa}$

$P_{\mathrm{c}}=$ critical pressure, $\mathrm{MPa}$

$P_{\mathrm{r}}=$ reduced pressure

$R=$ universal gas constant, $8.314 \mathrm{~J} /(\mathrm{mol} \cdot \mathrm{K})$

$T$ = temperature, $\mathrm{K}$

$T_{\mathrm{c}}=$ critical temperature, $\mathrm{K}$

$T_{\mathrm{r}}=$ reduced temperature

$T_{r w}=$ reduced temperature of water

$V=$ molar volume, $\mathrm{m}^{3} / \mathrm{kmol}$

$w_{\mathrm{s}}=$ solvent weight fraction

$w_{\mathrm{b}}=$ heavy oil/bitumen weight fraction

$w_{\text {water }}=$ water weight fraction

$x_{\mathrm{s}}=$ solvent molar fraction

$x_{\mathrm{HC}}=$ molar fraction of diluted heavy oil/bitumen in oleic phase of a solvents-heavy oil/bitumen-water system $x_{\mathrm{w}}=$ molar fraction of water in oleic phase of a solventsheavy oil/bitumen-water system

$y_{i}=$ mole fraction of the $i$ th component in the mixture

$y_{j}=$ mole fraction of the $j$ th component in the mixture

\section{ABBREVIATIONS}

AARD = absolute average relative deviation

\section{GREEK LETTERS}

$\alpha=\alpha$ function in PR EOS

$\alpha_{\mathrm{H}_{2} \mathrm{O}}=\alpha$ function for water in PR EOS

$\delta_{i j}=$ BIP between the $i$ th and $j$ th component in the mixture

$\omega=$ acentric factor

$\mu_{\mathrm{s}}=$ dynamic viscosity of solvent, $\mathrm{mPa} \cdot \mathrm{s}$

$\mu_{\mathrm{b}}=$ dynamic viscosity of heavy oil/bitumen, $\mathrm{mPa} \cdot \mathrm{s}$

$\mu_{i}^{\text {cal }}=i$ th calculated oleic phase viscosity, $\mathrm{mPa} \cdot \mathrm{s}$

$\mu_{i}^{\text {exp }}=i$ th measured oleic phase viscosity, $\mathrm{mPa} \cdot \mathrm{s}$

$\mu_{\mathrm{m}}=$ viscosity of mixture, $\mathrm{mPa} \cdot \mathrm{s}$

$\mu_{\mathrm{HC}}=$ viscosity of diluted heavy oil/bitumen in oleic phase of a solvents-heavy oil/bitumen-water system, $\mathrm{mPa} \cdot \mathrm{s}$

$\mu_{\mathrm{w}}=$ viscosity of water, $\mathrm{mPa} \cdot \mathrm{s}$

$\varphi_{\mathrm{s}}=$ solvent volume fraction under ambient conditions

$\varphi_{\mathrm{b}}=$ heavy oil/bitumen volume fraction under ambient conditions

$\nu_{\mathrm{s}}=$ kinematic viscosity of solvent, $\mathrm{m}^{2} / \mathrm{s}$

$\nu_{\mathrm{b}}=$ kinematic viscosity of heavy oil/bitumen, $\mathrm{m}^{2} / \mathrm{s}$

$\nu_{\mathrm{m}}=$ kinematic viscosity of solvents-heavy oil/bitumen mixtures, $\mathrm{m}^{2} / \mathrm{s}$

$\eta_{s}=$ intermediate quantity for solvent in Lobe's mixing rule

$\eta_{\mathrm{b}}=$ intermediate quantity for heavy oil/bitumen in Lobe's mixing rule

$\theta=$ adjustable parameter in Shu's mixing rule which is in the range of 0 to 1

$\rho_{\mathrm{b}}=$ heavy oil/bitumen density, $\mathrm{kg} / \mathrm{m}^{3}$

$\rho_{\mathrm{s}}=$ solvent density, $\mathrm{kg} / \mathrm{m}^{3}$

$\rho_{\mathrm{s}}^{\text {eff }}=$ effective density of dissolved gas, $\mathrm{kg} / \mathrm{m}^{3}$

$\rho_{\mathrm{b}}^{\text {eff }}=$ effective density of heavy oil/bitumen, $\mathrm{kg} / \mathrm{m}^{3}$

$\rho_{\text {water }}^{\text {eff }}=$ effective density of water, $\mathrm{kg} / \mathrm{m}^{3}$

$\rho_{\mathrm{CO}_{2}}^{\text {eff }}=$ effective density of $\mathrm{CO}_{2}, \mathrm{~kg} / \mathrm{m}^{3}$

$\rho_{\mathrm{m}}=$ density of the liquid mixture, $\mathrm{kg} / \mathrm{m}^{3}$

\section{REFERENCES}

(1) Upreti, S. R.; Lohi, A.; Kapadia, R. A.; El-Haj, R. Vapor extraction of heavy oil and bitumen: A review. Energy Fuels 2007, 21 (3), 1562-1574. 
(2) Ivory, J.; Chang, J.; Coates, R.; Forshner, K. Investigation of cyclic solvent injection process for heavy oil recovery. J. Can. Pet. Technol. 2010, 49 (9), 22-23.

(3) Mohammadzadeh, O.; Rezaei, N.; Chatzis, I. Production characteristics of the steam-assisted gravity drainage (SAGD) and solvent-aided SAGD (SA-SAGD) processes using a 2-D macroscale physical model. Energy Fuels 2012, 26 (7), 4346-4365.

(4) Luo, S.; Barrufet, M. A. Reservoir simulation study of water-in-oil solubility effect on oil recovery in steam injection process. SPE Res. Eval. Eng. 2005, 8 (6), 528-533.

(5) Al-Murayri, M. T.; Maini, B. B.; Harding, T. G.; Oskouei, J. Multicomponent solvent co-injection with steam in heavy and extraheavy oil reservoirs. Energy Fuels 2016, 30 (4), 2604-2616.

(6) Glandt, C. A.; Chapman, W. G. Effect of water dissolution on oil viscosity. SPE Res. Eng. 1995, 10 (1), 59-64.

(7) Venkatramani, A. V.; Okuno, R. Compositional mechanisms in steam-assisted gravity drainage and expanding-solvent steam assisted gravity drainage with consideration of water solubility in oil. SPE Res. Eval. Eng. 2017, 20 (3), 681-697.

(8) Zheng, S.; Yang, D. Pressure maintenance and improving oil recovery by means of immiscible water-alternating- $\mathrm{CO}_{2}$ processes in thin heavy-oil reservoirs. SPE Res. Eval. Eng. 2013, 16 (1), 60-71.

(9) Chen, Z.; Zhao, X. Enhancing heavy-oil recovery by using middle carbon alcohol-enhanced hot polymer flooding. J. Pet. Sci. Eng. 2017, 149, 193-202.

(10) Simon, R.; Graue, D. J. Generalized correlations for predicting solubility, swelling and viscosity behavior for $\mathrm{CO}_{2}$-crude oil systems. J. Pet. Technol. 1965, 17 (1), 102-106.

(11) Ramos-Pallares, F.; Schoeggl, F. F.; Taylor, S. D.; Satyro, M. A.; Yarranton, H. W. Predicting the viscosity of hydrocarbon mixtures and diluted heavy oils using the expanded fluid model. Energy Fuels 2016, 30 (3), 3575-3595.

(12) Centeno, G.; Sánchez-Reyna, G.; Ancheyta, J.; Muñoz, J. A. D.; Cardona, N. Testing various mixing rules for calculation of viscosity of petroleum blends. Fuel 2011, 90 (12), 3561-3570.

(13) Pedersen, K. S.; Fredenslund, A. Viscosity of crude oils. Chem. Eng. Sci. 1984, 39 (6), 1011-1016.

(14) Quiñones-Cisneros, S. E.; Zéberg-Mikkelsen, C. K.; Stenby, E. $\mathrm{H}$. The friction theory ( $f$-theory) for viscosity modeling. Fluid Phase Equilib. 2000, 169 (2), 249-276.

(15) Quiñones-Cisneros, S. E.; Andersen, S. I.; Creek, J. Density and viscosity modeling and characterization of heavy oils. Energy Fuels 2005, 19 (4), 1314-1318.

(16) De La Porte, J. J.; Kossack, C. A. A liquid phase viscositytemperature model for long-chain $n$-alkanes up to $\mathrm{C}_{64} \mathrm{H}_{130}$ based on the free volume theory. Fuel 2014, 136, 156-164.

(17) Ramos-Pallares, F.; Lin, H.; Yarranton, H. W.; Taylor, S. D. Prediction of the liquid viscosity of characterized crude oils by use of the generalized Walther model. SPE J. 2017, 22 (5), 1487-1505.

(18) Gates, I. D. Oil phase viscosity behaviour in expanding-solvent steam-assisted gravity drainage. J. Pet. Sci. Eng. 2007, 59 (1-2), 123134.

(19) Nourozieh, H.; Kariznovi, M.; Abedi, J. Measurement and modeling of solubility and saturated-liquid density and viscosity for methane/Athabasca-bitumen mixtures. SPE J. 2016, 21 (1), 180-189.

(20) Mehrotra, A. K.; Svrcek, W. Y. Viscosity of compressed Cold Lake bitumen. Can. J. Chem. Eng. 1987, 65 (4), 672-675.

(21) Nourozieh, H.; Kariznovi, M.; Abedi, J. Viscosity measurement and modeling for mixtures of Athabasca bitumen $/ n$-pentane at temperatures up to $200^{\circ} \mathrm{C}$. SPE J. 2015, 20 (2), 226-238.

(22) Nourozieh, H.; Kariznovi, M.; Abedi, J. Viscosity measurement and modeling for mixtures of Athabasca bitumen/hexane. J. Pet. Sci. Eng. 2015, 129, 159-167.

(23) Gao, J.; Okuno, R.; Li, H. A phase-behavior for $n$-hexane/ bitumen and $n$-octane/bitumen mixtures. SPE J. 2018, 23 (1), 128144.

(24) Li, X.; Li, H.; Yang, D. Determination of multiphase boundaries and swelling factors of solvent(s) $-\mathrm{CO}_{2}$-heavy oil systems at high pressures and elevated temperatures. Energy Fuels 2013, 27 (3), $1293-1306$

(25) Li, H.; Zheng, S.; Yang, D. Enhanced swelling effect and viscosity reduction of solvent(s)/CO $/$ heavy-oil systems. SPE J. 2013, 18 (4), 695-707.

(26) Li, X.; Han, H.; Yang, D.; Liu, X.; Qin, J. Phase behavior of $\mathrm{C}_{3} \mathrm{H}_{8}-\mathrm{CO}_{2}$-heavy oil systems in the presence of aqueous phase under reservoir conditions. Fuel 2017, 209, 358-370.

(27) Zirrahi, M.; Hassanzadeh, H.; Abedi, J. Experimental and modeling studies of MacKay River bitumen and water. J. Pet. Sci. Eng. 2017, 151 (2), 305-310.

(28) Nourozieh, H.; Kariznovi, M.; Abedi, J. Density and viscosity of Athabasca bitumen samples at temperatures up to $200^{\circ} \mathrm{C}$ and pressures up to $10 \mathrm{MPa}$. SPE Res. Eval. Eng. 2015, 18 (3), 375-386.

(29) Freitag, N. P.; Kristoff, B. J. Comparison of carbon dioxide and methane as additives at steamflood conditions. SPE J. 1998, 3 (1), 14-18.

(30) Nourozieh, H.; Kariznovi, M.; Abedi, J. Experimental and modeling studies of phase behavior for propane/Athabasca bitumen mixtures. Fluid Phase Equilib. 2015, 397, 37-43.

(31) Nourozieh, H.; Kariznovi, M.; Abedi, J. Solubility of $n$-butane in Athabasca bitumen and saturated densities and viscosities at temperatures up to $200^{\circ} \mathrm{C}$. SPE J. 2017, 22 (1), 94-102.

(32) Kariznovi, M. Phase behaviour study and physical properties measurement for Athabasca bitumen/solvent systems applicable for thermal and hybrid solvent recovery processes. Ph.D. Dissertation; University of Calgary: Calgary, AB, 2013.

(33) Zirrahi, M.; Hassanzadeh, H.; Abedi, J. Experimental and modeling studies of water, light $n$-alkanes and MacKay River bitumen ternary systems. Fuel 2017, 196, 1-12.

(34) Mehrotra, A. K.; Svrcek, W. Y. Properties of Cold Lake bitumen saturated with pure gases and gas mixtures. Can. J. Chem. Eng. 1988, 66 (4), 656-665.

(35) Peng, D. Y.; Robinson, D. B. A new-constant equation of state. Ind. Eng. Chem. Fund. 1976, 15 (1), 59-64.

(36) Chen, Z.; Yang, D. Optimization of the reduced temperature associated with Peng-Robinson equation of state and Soave-RedlichKwong equation of state to improve vapor pressure prediction for heavy hydrocarbon compounds. J. Chem. Eng. Data 2017, 62 (10), $3488-3500$.

(37) Li, X.; Yang, D. Determination of mutual solubility between $\mathrm{CO}_{2}$ and water by using the Peng-Robinson equation of state with modified alpha function and binary interaction parameter. Ind. Eng. Chem. Res. 2013, 52 (38), 13829-13838.

(38) Chen, Z.; Yang, D. Quantification of phase behaviour of solvents-heavy oil systems in the presence of water at high pressures and elevated temperatures. Fuel 2018, 232, 803-816.

(39) Twu, C. H. An internally consistent correlation for predicting the critical properties and molecular weights of petroleum and coal-tar liquids. Fluid Phase Equilib. 1984, 16 (2), 137-150.

(40) Computer Modelling Group Ltd. WinProp phase property program; Computer Modelling Group Ltd.: Calgary, AB, 2011.

(41) Chen, Z.; Yang, D. Prediction of phase behaviour for $n$ alkane- $\mathrm{CO}_{2}$-water systems with consideration of mutual solubility using Peng-Robinson equation of state. J. Supercrit. Fluids 2018, 138, 174-186.

(42) Chen, Z.; Yang, D. Determination of mutual solubility between $n$-alkanes/ $n$-alkylbenzenes and water by using Peng-Robinson equation of state with modified alpha functions and generalized BIP correlations. Fluid Phase Equilib. 2018, 477, 19-29.

(43) Arrhenius, S. A. Über die Dissociation der in Wasser gelösten Stoffe. Z. Phys. Chem. 1887, 1, 631-648.

(44) Kendall, J.; Monroe, K. The viscosity of liquids II. The viscosity-composition curve for ideal liquid mixtures. J. Am. Chem. Soc. 1917, 39 (9), 1787-1802.

(45) Cragoe, C. S. Changes in the viscosity of liquids with temperature, pressure and composition. Presented at the 1st World Petroleum Congress, London, July 18-24, 1933; WPC-201. 
(46) Lobe, V. M. A model for the viscosity of liquid-liquid mixtures. M.Sc. Thesis; University of Rochester: Rochester, NY, 1973.

(47) Shu, W. R. A viscosity correlation for mixtures of heavy oil, bitumen, and petroleum fractions. SPE J. 1984, 24 (3), 277-282.

(48) Yarranton, H.; Van Dorp, J.; Verlaan, M. Wanted dead or live: Crude-cocktail viscosity-A pseudocomponent method to predict the viscosity of dead oils, live oils, and mixtures. J. Can. Pet. Technol. 2013, 52 (3), 176-191.

(49) Lemmon, E. W.; McLinden, M. O.; Friend, D. G. Thermophysical properties of fluid systems. In NIST Chemistry WebBook, NIST Standard Reference Database Number 69; Linstrom, P. J., Mallard, W. G., Eds.; National Institute of Standards and Technology: Gaithersburg, MD, 2012.

(50) Tharanivasan, A.; Yarranton, H.; Taylor, S. Application of a regular solution-based model to asphaltene precipitation from live oils. Energy Fuels 2011, 25 (2), 528-538.

(51) Saryazdi, F. Density prediction for mixtures of heavy oil and solvents. M.A.Sc.; University of Calgary: Calgary, $\mathrm{AB}, 2012$. 